\title{
What are the effects of maternal and pre-adult environments on ageing in humans, and are there lessons from animal models?
}

\author{
Paul M. Brakefield ${ }^{\mathrm{a}, *}$, David Gems ${ }^{\mathrm{b}}$, Tim Cowen ${ }^{\mathrm{c}}$, Kaare Christensen ${ }^{\mathrm{d}}$, \\ Beatrix Grubeck-Loebenstein ${ }^{\mathrm{e}}$, Laurent Keller ${ }^{\mathrm{f}}$, Jim Oeppen ${ }^{\mathrm{g}}$, \\ Angeles Rodriguez-Pena ${ }^{\mathrm{h}}$, Maria Antonietta Stazi ${ }^{\mathrm{i}}$, Marc $\operatorname{Tatar}^{\mathrm{j}}$, Rudi G.J. Westendorp ${ }^{\mathrm{k}}$ \\ ${ }^{a}$ Institute of Biology, Leiden University, PO Box 9516, 2300 RA Leiden, The Netherlands \\ ${ }^{\mathrm{b}}$ Department of Biology, University College London, Gower Street, London WC1E 6BT, UK \\ ${ }^{\mathrm{c}}$ Department of Anatomy and Developmental Biology, Royal Free and University College Medical School, \\ Royal Free Campus, Rowland Hill Street, Hampstead, London NW3 2PF, UK \\ ${ }^{\mathrm{d}}$ University of Southern Denmark, Sdr. Boulevard 23A, Odense C 5000, Denmark \\ ${ }^{\mathrm{e}}$ Institüt für Biomedizinische Alternforschung, Austrian Academy of Sciences, Rennweg 10, Innsbruck 6020, Austria \\ ${ }^{\mathrm{f}}$ Université de Lausanne, Institut d'Écologie, Bâtiment de Biologie, Lausanne 1015, Switzerland \\ ${ }^{\mathrm{g}}$ Department of Geography, University of Cambridge, Downing Place, Cambridge CB2 3EN, UK \\ ${ }^{\mathrm{h}}$ Instituto Investigaciones Biomedicas CSIC-UAM, Arturo Duperier, 4, Madrid 20829, Spain \\ i Instituto Superiore di Sanità, Viale Regina Elena 229, Roma 00161, Italy \\ ${ }^{\mathrm{j}}$ Department of Ecology and Evolutionary Biology, Brown University, Box G-W, Providence, Rhode Island 02912, USA \\ ${ }^{\mathrm{k}}$ Gerontology and Geriatrics, Leiden University Medical Centre C2-R, PO Box 9600, 2300 RC Leiden, The Netherlands
}

Received 16 July 2004; accepted 24 July 2004

Available online 20 October 2004

\begin{abstract}
An open issue in research on ageing is the extent to which responses to the environment during development can influence variability in life span in animals, and the health profile of the elderly in human populations. Both affluence and adversity in human societies have profound impacts on survivorship curves, and some of this effect may be traceable to effects in utero or in infancy. The Barker Hypothesis that links caloric restriction in very early life to disruptions of glucose-insulin metabolism in later life has attracted much attention, as well as some controversy, in medical circles. It is only rarely considered by evolutionary biologists working on phenotypic plasticity, or by biogerontologists studying model organisms such as C. elegans or Drosophila. One crucial mechanism by which animals can respond in an adaptive manner to adverse conditions, for example in nutrition or infection, during development is phenotypic plasticity. Here we begin with a discussion of adaptive plasticity in animals before asking what such phenomena may reveal of relevance to rates of ageing in animals, and in humans. We survey the evidence for effects on adult ageing of environmental conditions during development across mammalian and invertebrate model organisms, and ask whether evolutionary conserved mechanisms might be involved. We conclude that the Barker Hypothesis is poorly supported and argue that more work in human populations should be integrated with multi-disciplinary studies of ageingrelated phenomena in experimental populations of different model species that are subjected to nutritional challenges or infections during preadult development.
\end{abstract}

(C) 2004 Elsevier Ireland Ltd. All rights reserved.

Keywords: Ageing; Phenotypic plasticity; Adaptation; Evolution; Model organisms; Barker hypothesis

\footnotetext{
* Corresponding author. fax: +31715274900 .

E-mail address: brakefield@rulsfb.leidenuniv.nl (P.M. Brakefield).
}

\section{Adaptive phenotypic plasticity in animals}

Phenotypic plasticity refers to variation in the phenotype - for example, morphology, life history, behaviour, or metabolism - of a given genotype when individuals 
complete their development in different environments (Schlichting and Pigliucci, 1998). Some amount of plasticity across environments is an almost ubiquitous feature of phenotypic variation. In some such cases, variation in the phenotype may reflect a form of developmental constraint, an inability across environments to map phenotypes in a highly repeatable manner onto underlying genetic variation. Variability in the environment during growth may influence development in minor, largely unpredictable, ways to result in quantitative variation in the phenotype. Environmental challenges of a particular nature may lead to more predictable but still rather subtle effects on development. Much effort in animal studies has been directed at understanding the evolution of more discrete or alternative phenotypes, usually involving sets of traits or a syndrome, that are produced in response to alternative environments during pre-adult development. When such extreme examples of plasticity are adaptive, a physiological mechanism in response to an environmental cue perceived during ontogeny regulates alternative paths of development to the adult phenotype (Fig. 1A). The cue acts as a predictor for the environment in which a specific regime of natural selection is expected for the adults of a particular phenotypic class. In many cases, phenotypic plasticity has indeed evolved as such an adaptive response to recurrent patterns of environmental heterogeneity, either in time or space.

Phenotypic plasticity is of interest to evolutionary biologists as a potential means of adaptation to divergent environments whilst minimising any genetic load resulting from individuals that are mismatched to their environment. To developmental biologists, phenotypic plasticity provides attractive material to understand more about the control of development via physiological mechanisms that regulate gene expression during ontogeny (Brakefield et al., 2003). From a genetic perspective, whilst sensitivity to the environment during development at alleles of many genes may be involved, whether there are specific regulatory genes that determine plasticity and how they function is especially interesting. More complete descriptions of such 'genes for plasticity' may take us closer to understanding developmental switches via 'gatekeeping' systems such as that involved in regulating human puberty (e.g. Seminara et al., 2003). Genomics approaches will reveal not only how cascades of gene expression change following the initial response to the environmental cue and downstream of such controls of development, but also how they differ among the alternative adult phenotypes following development. The roles of epigenetic processes and of gene imprinting in the control of developmental plasticity remain unknown. Another issue of interest is the contrast between the diverse responses which characterise plasticity, and genetic canalisation, in which a single genotype yields similar phenotypes in different environments and where developmental properties tend to limit variation in the final phenotype. Integrating genetical studies of canalisation and plasticity should enable novel insights about the concept of developmental stability.

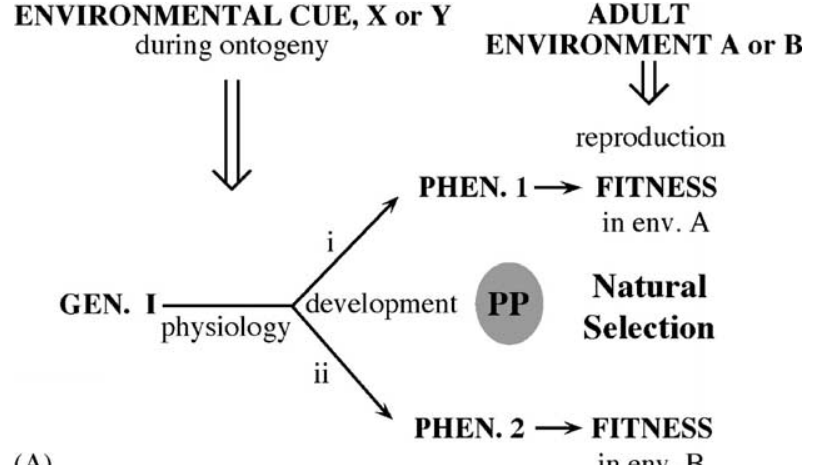

(A)

in env. B

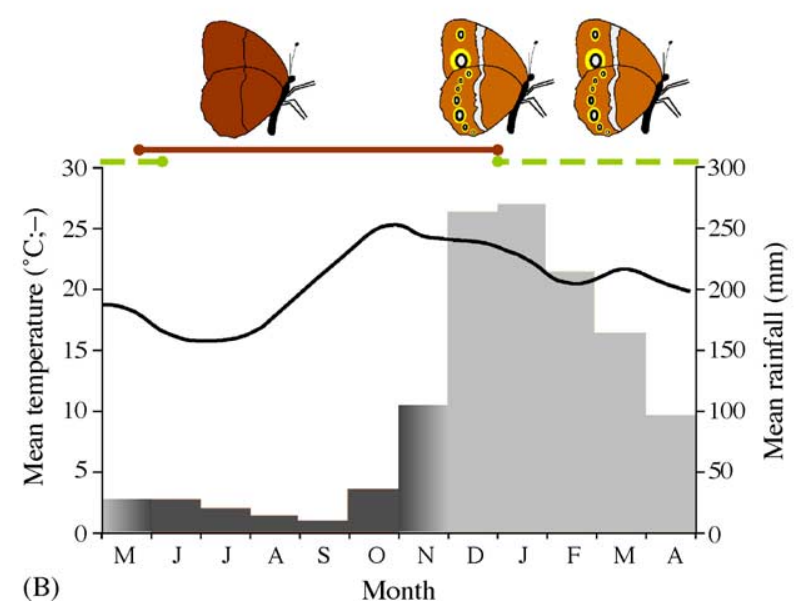

Fig. 1. (A) Scheme showing the basic components of phenotypic plasticity (PP) in which two alternative forms (adult phenotypes 1 and 2) can be produced by development from a single genotype (I). An environmental cue for the adult environment acts via physiological mechanisms to modulate the pathway of development ( $\mathrm{i}$ or ii). If the phenotypic plasticity is adaptive then natural selection yields a higher relative fitness for each form in the environment (A or B) in which it spends most of its adult life. (B) An example of this mode of plasticity involving responses to wet-dry seasonal cycles in Bicyclus butterflies in East Africa. A dry season is followed by a wet season (dark and light grey, respectively). Two generations of the wet season form (WSF) with conspicuous eyespots occur in each rainy season. Larvae of both of these cohorts develop at high average temperatures. The second WSF generation reproduces before food plants die out, and the larvae develop at progressively declining temperatures. This cohort produces the generation of the dry season form (DSF) without eyespots that persists through the period of low rainfall (redrawn from Brakefield and Reitsma (1991)).

Adaptive developmental plasticity is exemplified in the seasonal forms of Bicyclus butterflies in parts of Africa where active adults of different generations fly in each of the alternating dry and wet seasons (Fig. 1B). The alternative seasonal forms are adapted to the particular seasonal environment in which they spend most of their adult life (Beldade and Brakefield, 2002; Lyytinen et al., 2004), and are produced in response to low or high temperature during larval growth. The differences in temperature lead to changes in timing of release of ecdysteroid hormones in early pupae, which in turn modulates known developmental pathways of wing pattern formation (Brakefield et al., 1996, 1998). 


\section{Phenotypic plasticity and ageing}

The emphasis in work on adaptive phenotypic plasticity has been in linking processes during development with patterns of variation in fitness in adults. The dry season environment of Bicyclus butterflies is considered comparatively stressful or adverse, both with respect to larval development and for most of adult life (which is greatly extended), whilst the favourable wet season environment is uniformly rich in nutrients and other resources (Fig. 1B). This has clearly led to the evolution of a phenotypic syndrome involving not only wing pattern differentiation but a suite of life history and metabolic traits (see Zijlstra et al., 2003). Such differences in development and in adult phenotype have consequences for survival to maturity and for timing of reproduction in the environments in which adults live, but may also influence their rates of ageing (Fig. 2). This latter issue is currently a topic of investigation in these butterflies.

There will clearly continue to be excellent opportunities to unravel the consequences of developmental plasticity for longevity and the rate of ageing in model organisms, especially baker's yeast (Guarente and Kenyon, 2000), nematodes (Kenyon, 2001; Leroi, 2001) and fruitflies (Partridge and Gems, 2002; Zwaan, 2003). The nematode C. elegans also shows phenotypic plasticity during development. Under favourable nutritional conditions, larvae develop through four stages into reproductive adults. However, where conditions are not favourable for reproduction (limited food, high population density, high temperature), larvae develop into a morphologically distinct diapausal form of the third stage, or dauer larva (Cassada and Russell, 1975; Riddle and Albert, 1997). Dauer larvae are stress-resistant and non-feeding (their buccal cavity is occluded) surviving on stored lipid and glycogen. They are also long-lived, surviving up to 90 days (compared to a 2-3 weeks lifespan in reproductive adults). Should conditions become more suitable for reproduction, dauer larvae can resume development and form reproductive adults. A more limited form of larval diapause, or larval stop, has been observed in larvae of Drosophila developing in conditions of

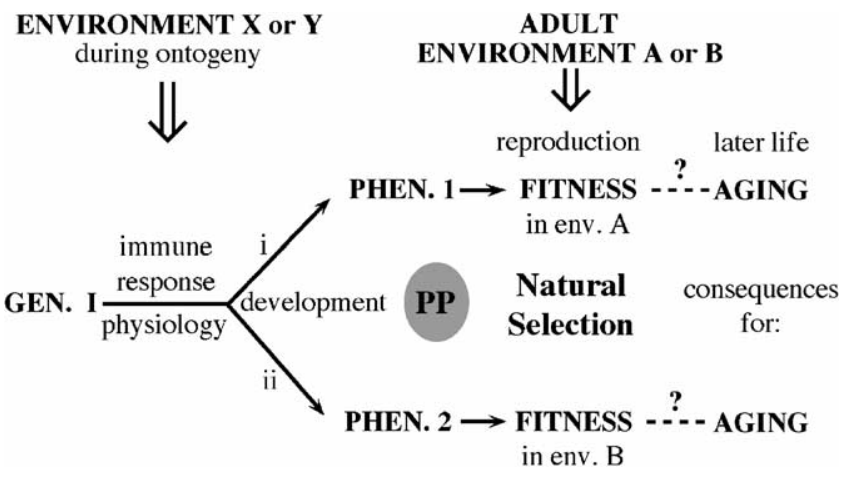

Fig. 2. The scheme for the generation of phenotypic plasticity from Fig. 1A with additions of potential relevance for ageing-related phenomena. overcrowding and low nutrient availability (Mensua and Moya, 1983).

Both the dauer larva in nematodes, and the larval stop in Drosophila involve diapause and delayed development in response to limited nutrient availability. The developmental response of larvae to dietary restriction (DR) may involve similar mechanisms to the effect of DR on the adult. DR exerted during adulthood extends lifespan and reduces fertility in both C. elegans (Klass, 1977; Lakowski and Hekimi, 1998) and Drosophila melanogaster (Chapman and Partridge, 1996; Nusbaum and Rose, 1999). A similar and perhaps related phenomenon is hibernation, which can extend lifespan, as in the Turkish hamster Mesocricetus brandti (Lyman et al., 1981). Thus, larval diapause, the effects of DR, and hibernation all entail deferral of reproduction and extension of lifespan in response to an environment unsuitable for reproduction. But a major difference between dauer diapause and the effects of DR on adults is that the former involves formation of an anatomically distinct morph. Arguably, environmentally regulated formation of morphs with different lifespans represents a more advanced, descendent form of plasticity, derived from simpler and more limited responses to DR seen in adults. Further striking forms of morph-associated phenotypic plasticity in ageing are seen in social insects, such as honeybees and ants (Robinson, 1992; Keller and Genoud, 1997), discussed below.

The question at issue here is whether environmental effects on development affect adult ageing, or: are there mechanisms for retaining a "memory" of developmental experience into adulthood? In the case of $C$. elegans, the lifespan of adults derived from dauer larvae is unaffected by the prior dauer state, or by the length of time that dauer diapause endures (Klass and Hirsh, 1976). Dauer larvae have therefore been considered as non-ageing, and it has been suggested that their lifespan might be limited only by their nutrient supplies. However, recent studies suggest that dauer larvae do, in fact, age, but that exit from dauer involves a process of rejuvenation (Houthoofd et al., 2002). The dauer/ non-dauer decision in early development is controlled by several signalling pathways, including an insulin/IGF-1 signalling (IIS) pathway. Reduction of signalling via this pathway can lead to constitutive dauer larva formation, or increased adult lifespan (Friedman and Johnson, 1988; Kenyon et al., 1993; Kimura et al., 1997). Reduction of IIS confined to larval stages did not increase adult lifespan, whereas reduced IIS during adulthood alone greatly increased lifespan (Dillin et al., 2002a). Taken together, these findings strongly imply that $C$. elegans does not possess a system for translating larval environmental cues into adult phenotypic plasticity (although it should be noted that very little is known about potential cues in the wild). In particular, the lack of effect on the adult of perturbation of IIS during development is not consistent with the occurrence of a Barker Effect in C. elegans. This conclusion is supported by observations in Drosophila. Nutrient- or yeast- 
challenged Drosophila larvae show effects on adult body size but limited consequences for adult life span.

Although these observations in nematodes and fruitflies suggest that the larval environment has little effect on ageing, there is a recent example that reveals effects on adult ageing of larval events. In C. elegans, larval-confined knock-down of function of several genes associated with mitochondrial function leads to increased adult lifespan in the laboratory (Dillin et al., 2002b). This raises the possibility that mitochondrial function is a focus for imprinting of influences of developmental environment for long term life history responses. In this context, it is perhaps significant that mutations in a number of $C$. elegans genes associated with mitochondrial function, e.g. clk-1, retard larval development and increase adult lifespan (Wong et al., 1995; Hekimi et al., 1998; Felkai et al., 1999). It will be important to explore these effects more fully in both affluent and adverse adult environments. Hints of a 'memory' of fetal-growth restriction leading to affects on the lifespan of adult male mice have recently been published (Ozanne and Hales, 2004), emphasising the need for further work in higher organisms. Another important issue concerns whether all, or only specific, tissues respond to such stimuli.

Non-model organisms with variable and experimentally tractable lifespans and with particularly relevant ecologies or social behaviour are also likely to prove especially useful in revealing novel interactions between development and diverse aspects of ageing. One unusual and particularly interesting system occurs in ants where there are three main phenotypic classes of individuals that differ greatly in lifespan. The queens which are the reproductive females are extraordinarily long-lived (up to 30 years in some species; Keller and Genoud, 1997). The workers which are the nonreproductive females have a much shorter lifespan ranging from a few months to 1-2 years depending on species. Finally, males are the more short-lived, with a lifespan of a few weeks only. Importantly, these dramatic differences although associated with different castes are not coupled with differences in genotype; diploid brood can develop into either queens or workers, the developmental switch being modulated by insect hormones in response to the social environment in which larvae develop. Interestingly, the longer lifespan of queens is apparently not associated with a lower metabolic rate as they have to produce large numbers of eggs every day.

The comparison of gene expression between castes provides an ideal system to investigate the genetic basis of long lifespan. A candidate gene approach can be used to compare the expression level of genes that have been implicated as being involved in ageing in other organisms. For example, there is evidence that over-expression of the enzyme $\mathrm{Cu}-\mathrm{Zn}$ superoxide dismutase 1 (SOD1) can lengthen lifespan of D. melanogaster in the laboratory. However, a comparison of SOD1 expression levels between queens, workers and males of the ant Lasius niger showed no evidence of a higher expression in the longer-lived castes (Parker et al., 2004). In fact, queens had slightly lower levels of SOD1 expression, and values similar to D. melanogaster; indeed the significance of studies of ageing in Drosophila that involve overexpression of antioxidant enzymes has recently been challenged (Orr and Sohal, 2003). Another approach is to identify new ageing genes by using wider genome screening that compares levels of expression of a large number of genes among castes. This is becoming viable now that the first ant microarray for the fire ant Solenopsis invicta is in development (L. Keller, unpublished).

A further example of extreme phenotypic plasticity in ageing is seen among genetically identical adults morphs in the parasitic nematode Strongyloides ratti (reviewed in Gems, 2001). In this species there are both free-living and parasitic adults. The latter dwell in the intestine of rodents. Their progeny pass out into the soil, and can develop into parasitic infective larvae, or free-living adults, depending on environmental cues (Viney, 1999). While the lifespan of the parasitic adult is about 1 year (Gemmill et al., 1997), freeliving adults age at an accelerated rate, and have a mean lifespan of only 2-3 days (Gardner et al., 2004).

Is there any sense in which morphs with different patterns of ageing occur in mammals? In some respects, the occurrence of males and females is analogous to the formation of different castes of honeybee or termite. Many animal species exhibit major sex differences in ageing, including nematodes (Gems and Riddle, 2000; McCulloch and Gems, 2003) and fruitflies (Clancy et al., 2001; Magwere et al., 2004). Humans also show a gender gap of some 4-6 years in life expectancy in developed countries (Smith, 1993). The extent to which ageing in humans is influenced by perturbations in sexual development is virtually unexplored. However, it is well understood that sexual development affects the ageing of the immune system in humans, as gonadectomy prevents involution of the thymus, while the thymus gland undergoes involution after testosterone and estrogen treatment, but not progesterone, following gonadectomy (Oner and Ozan, 2002).

\section{Environmental plasticity and ageing in humans; perspectives}

An important issue is whether mechanisms to convert environmental effects or development into plastic responses are evolutionarily conserved (or public) or whether they are limited to particular animal types (i.e. private) (Martin et al., 1996). The invertebrate systems discussed above possess fundamental differences in biology to vertebrate models and humans. For example, much of the adult nematode and fly is remodelled during larval moults, especially in metamorphosis in the fruitfly. The somatic component of the adult organism is also largely or completely post-mitotic. Such differences with vertebrates may affect the likelihood of 
finding some trace or 'memory' of pre-adult environment in the rate of ageing.

Much of the evidence about the effects of developmental plasticity on ageing has come from whole organism studies, particularly those of effects on lifespan. However, the substrate in which plasticity is expressed, and which likely influences significantly the outcome of early life plasticity in relation to ageing, is cells and the tissues which they make up. Two groups of cells-those of the immune and nervous systems-have begun to be studied in this connection.

Infectious organisms and diseases represent a crucial environmental challenge where another difference between lower and higher organisms is relevant: invertebrates have an innate immune response whilst higher vertebrates also have an acquired immunity system whereby experience during development can affect adult fitness, including ageing (Franceschi et al., 2000). The immune response in Drosophila is a useful model to study the principles of innate immunity (Hultmark, 2003). Many mechanisms are, however, conserved between invertebrates and mammals. There is now good evidence that a variety of intruding microorganisms or parasites are recognised by a fixed set of recognition molecules. The signalling pathways via which these molecules trigger an immune response have now been dissected in detail. However, while any substantial role for plasticity in innate immunity may be unlikely, this is not so for acquired immunity in vertebrates. Thus, latent infection with CMV that frequently occurs early in human life, leads to a continuous antigenic stimulation of the immune system. The accumulation of terminally differentiated CD8+ and CD4+ T cells is the result (Kern et al., 2002). These cells, which have a phenotype strongly reminiscent of senescent fibroblasts and keratinocytes, do not proliferate, but produce large amounts of IFN $\gamma$ (Saurwein-Teissl et al., 2002). Ubiquitous stimulation of inflammatory processes and decreased humoral immunity are the consequence (Saurwein-Teissl et al., 2002; Trzonkowski et al., 2003). Terminally differentiated $\mathrm{T}$ cells mostly occur as large expanded clones which leads to a restriction in the diversity of the immunological repertoire in old age (Khan et al., 2002).

Developmental plasticity in many guises is a key characteristic of the nervous systems of all animals. Importantly for the present discussion, this group of cells, like those of the immune system, retain an enormous capacity to respond to altered functional demand throughout adult life, and this is true of the snail as of mammals such as ourselves (Pittenger and Kandel, 2003). It begins to appear that the nervous system has a profound and well-conserved regulatory influence on lifespan. This probably follows on from its central role in insulin-like signalling, as, for example, in worms (Wolkow et al., 2000), flies (Tatar et al., 2003) and mammals (Mobbs et al., 2001). What is less clear is how developmental responses to new environmental demands might influence ageing processes in the nervous system and/or its regulatory role in relation to lifespan.
Tempting clues come from studies of the effects of lifelong dietary restriction on the nervous system which show that the thrifty phenotype associated with extended lifespan in calorically restricted rodents includes enhanced neuronal stress responses (Roth et al., 1993), increased plasticity (Mattson et al., 2002) and marked protection against agerelated neuron cell death (Cowen et al., 2000). However, these studies have not so far included the crucial element of the effects on the ageing phenotype of altering early life conditions. One important observation in designing these experiments is the demonstration that partial starvation during embryonic and/or early postnatal life has deleterious effects on neuronal development, including the survival of important groups of central (Bedi, 2003) and peripheral (Santer and Conboy, 1990) neurons. It seems reasonable to predict therefore that early life caloric restriction will exert negative effects on later life neural plasticity while positive effects will result from its introduction during early (and perhaps later) adulthood. In mammals, this is entirely consistent with the existence of a regulatory programme synchronising independence from the protected maternal food supply with the emerging capacity to respond adequately to an altered environment. Clearly future research is likely to uncover many associations between the development of neural networks in early life and consequences for ageing-related phenomena in later life (for an example, see Borrell et al., 2002).

Arguably, developmental phenotypic plasticity with programmed, alternative phenotypes is less likely to evolve in a long-lived organism such as humans because most adult individuals will experience many environments during their life; the graininess of variation in the environment, both in time and space, is of a different scale to generation-time. Nevertheless, environmental effects in utero or pre-adult life that result in plasticity of development may have consequences at all stages of adult life. Those involving the nutritional environment and exposure to disease and pathogens are likely to be especially ubiquitous. The description and analysis of the signals and consequences of such plasticity has only just begun.

The regulation of alternative cascades of gene expression in development that result in alternative adult phenotypes may have implications in later life for gene expression, metabolism and resource allocation, and for cellular processes such as maintenance, repair and apoptosis. Some consequences of developmental plasticity may represent more or less direct ('programmed') effects on specific patterns of genetic expression in later life, while others could represent a more indirect by-product leading to general, detrimental effects on metabolism and on cellular processes such as proliferation, maintenance and repair in later life. It will become increasingly possible to track the mechanisms that underlie such interactions in particular populations of cells, in organelles and in organs (e.g. Taylor et al., 2003; and see previous discussion regarding immune and nervous systems) 
There are tantalising indications that the framework of thinking about phenotypic plasticity illustrated in Fig. 2B may be relevant to understanding the ageing process in human populations. The so-called Barker Hypothesis in humans has generated considerable interest. Periods of low nutrition and dietary restriction in utero or in early childhood appear to result in changes in regulation of growth and in glucose-insulin metabolism, and hence to so-called thrifty phenotypes in the adult (review in Hales and Barker, 2001). There is some evidence that an association exists between fetal growth and later life health outcomes such as blood pressure and cardiovascular mortality. The key question is, however, whether it is fetal nourishment or other factors such as genes or socioeconomic conditions that cause any association. Some studies suggest that socioeconomic confounding cannot explain the association between fetal growth and cardiovascular mortality (Leon et al., 1998), but they are few, and even fewer studies have evaluated the influence of genetic confounding. To avoid some of these problems, studies dealing with extreme conditions in early life, such as famine and twinning, are well suited. During the late 1990s, three reports addressed the influence of prenatal exposure to famine on health in later life, and no consistent pattern was found in the studies of the 1866-1868 Finnish famine (Kannisto et al., 1997), the siege of Leningrad in 1941-1942 (Stanner et al., 1997), and the Dutch hunger winter 1944-1945 (Ravelli et al., 1998; Roseboom et al., 1999).

Twin studies are relevant because twins experience severe growth retardation in the uterus, especially in the third trimester, and furthermore, studies of twins can control for the influence of the mother's socioeconomic status and for the effect of genes. If twins are "programmed" due to the considerable growth retardation during the third trimester, one could expect an increased mortality and especially an increased cardiovascular mortality in adulthood for twins compared to the general population. Both a Swedish and a Danish twin study found similar mortality patterns among twins and singletons in adulthood (Vågerö and Leon, 1994; Christensen et al., 1995). Furthermore, a study of causespecific mortality of 19,986 Danish twin individuals from the birth cohorts 1870-1930 followed from 1952 to 1993 showed no twin-singleton difference in cardiovascular mortality (Christensen et al., 1999). Hence the intra-uterine growth retardation experienced by twins leaves no 'scar' in terms of increased overall mortality or cardio-vascular mortality.

Whilst effects in later life along the lines of those proposed in the Barker Hypothesis appear poorly supported at present, we conclude that more studies are warranted. The adaptive nature of any developmental plasticity in humans is probably even more tenuous. However, there are intriguing ideas that such an adaptive component could be associated with the evolution of the thrifty phenotype in humans. Environments of early humans were probably more commonly associated with periods of dietary restriction in utero or in infants in such a way that the thrifty phenotype could have been favoured by natural selection. This may in turn have favoured the evolution of specific genes for plasticity to fine-tune the control of development of the phenotype in response to such environments. Thus the properties associated with thrifty phenotypes in later life in modern humans may reflect a ghost of a past period of natural selection in favour of the evolution of developmental plasticity (see Neel, 1962). Changes in diets and nutritional environments may then lead, at least in some genotypes, to patterns of gene expression during development, as well as in both early and later adult life, that may be either detrimental or beneficial to health and longevity in modern societies. There are many elements of speculation in such a scenario. The hope is that animal studies will reveal in detail, at the levels of gene and protein expression, and of tissue and organ growth and function, just which aspects of metabolism are programmed at different times of life in association with reduced or perturbed early growth. It is also to be hoped that comparative data will be forthcoming for natural populations of other mammals.

Perhaps the crucial issue in humans is to what extent, and under which circumstances, can a 'memory' or 'scar' of experiences in early life and development be detected in the rates of ageing, and can we understand why these patterns occur. An integrated, comparative programme of research on patterns of discrete developmental plasticity in invertebrate animal models with detailed studies of the effects of early environments in vertebrate model organisms is needed in the context of demographic and physiological observations relevant to the rate of ageing in human populations. This programme must encompass studies that link processes at the genetic, cellular, organ and whole organism levels. It must also involve exposing subjects to both favourable and high-stress environments during development and in later adult life, and be fully integrated with analytical surveys in human societies both in the developed and developing regions of the world. We propose a high priority for multidisciplinary studies involving replicated experimental populations of different model species that are subjected to unfavourable conditions of nutrition and/or infection during development. Cohorts from these populations would then be followed through the rest of their life to analyse the consequences of key challenges in early life for reproductive efforts and rates of ageing.

\section{References}

Bedi, K.S., 2003. Nutritional effects on neuron numbers. Nutr. Neurosci. 6 , 141-152.

Beldade, P., Brakefield, P.M., 2002. The genetics and evo-devo of butterfly wing patterns. Nat. Rev. Genet. 3, 442-452.

Borrell, J., et al., 2002. Prenatal immune challenge disrupts neurimotor gating in adult rats implications for ethiopathogenesis of schizophrenia. Neuropsychopharmacology 26, 204-215.

Brakefield, P.M., Reitsma, N., 1991. Phenotypic plasticity, seasonal climate and the population biology of Bicyclus butterflies (Satyridae) in Malawi. Ecol. Entomol. 16, 291-303. 
Brakefield, P.M., French, V., Zwaan, B.J., 2003. Development and the genetics of evolutionary change within insect species. Annu. Rev. Ecol. Evol. Syst. 34, 633-660.

Brakefield, P.M., Gates, J., Keys, D., Kesbeke, F., Wijngaarden, P.J., et al., 1996. Development, plasticity and evolution of butterfly wing patterns. Nature 384, 236-242.

Brakefield, P.M., Kesbeke, F., Koch, P.B., 1998. The regulation of phenotypic plasticity of eyespots in the butterfly Bicyclus anynana. Am. Nat. $152,853-860$

Cassada, R.C., Russell, R.L., 1975. The dauerlarva, a post-embryonic developmental variant of the nematode Caenorhabditis elegans. Dev. Biol. 46, 326-342.

Chapman, T., Partridge, L., 1996. Female fitness in Drosophila melanogaster: an interaction between the effect of nutrition and of encounter rate with males. Proc. Roy. Soc. London B 263, 755-759.

Christensen, K., Vaupel, J., Holm, N.V., Yashin, A.I., 1995. Twin mortality after age 6: fetal origins hypothesis versus twin method. Br. Med. J. 310, 432-436.

Christensen, K., Holm, N.V., McGue, M., Corder, L., Vaupel, J.W., 1999. A Danish population-based twin study on general health in the elderly. J. Ageing Health 11, 49-64.

Clancy, D., Gems, D., Harshman, L.G., Oldham, S., Hafen, E., et al., 2001. Extension of lifespan by loss of chico, a Drosophila insulin receptor substrate protein. Science 292, 104-106.

Cowen, T., Johnson, R.J.R., Soubeyre, V., Santer, R.M., 2000. Restricted diet rescues rat enteric motor neurones from age related cell death. Gut 47, 653-660.

Dillin, A., Crawford, D., Kenyon, C., 2002a. Timing requirements for insulin/IGF-1 signaling in C. elegans. Science 298, 830-834.

Dillin, A., Hsu, A., Arantes-Oliveira, N., Lehrer-Graiwer, J., Hsin, H., et al., 2002 b. Rates of behavior and ageing specified by mitochondrial function during development. Science 298, 2398-2401.

Felkai, S., Ewbank, J.J., Lemieux, J., Labbe, J.-C., Brown, G.G., et al., 1999. CLK-1 controls respiration, behavior and ageing in the nematode Caenorhabditis elegans. EMBO J. 18, 1783-1792.

Franceschi, C., Bonafe, M., Valensin, S., Olivieri, F., De Luca, M., et al., 2000. Inflamm-ageing. An evolutionary perspective on immunosenescence. Annu. NY Acad Sci. 908, 244-254.

Friedman, D.B., Johnson, T.E., 1988. A mutation in the age-1 gene in Caenorhabditis elegans lengthens life and reduces hermaphrodite fertility. Genetics 118, 75-86.

Gardner, M., Gems, D., Viney, M., 2004. Ageing in a very short-lived nematode. Exp. Gerontol. 39, 1267-1276.

Gemmill, A.W., Viney, M.E., Read, A.F., 1997. Host immune status determines sexuality in a parasitic nematode. Evolution 51, 393-401.

Gems, D., 2001. Ageing in free-living and parasitic nematodes. Biogerontology 1, 289-307.

Gems, D., Riddle, D.L., 2000. Genetic, behavioral and environmental determinants of male longevity in Caenorhabditis elegans. Genetics 154, 1597-1610.

Guarente, L., Kenyon, C., 2000. Genetic pathways that regulate ageing in model organisms. Nature 408, 255-262.

Hales, C.N., Barker, D.J.P., 2001. The thrifty phenotype hypotheis. Br. Med. Bull. 60, 5-20.

Hekimi, B., Lakowski, B., Barnes, T.M., Ewbank, J.J., 1998. Molecular genetics of life span in C. elegans: how much does it teach us? Trends Genet. 14, 14-20.

Houthoofd, K., Braeckman, B., Lenaerts, I., Brys, K., De Vreese, A., et al., 2002. Ageing is reversed, and metabolism is reset to young levels in recovering dauer larvae of C. elegans. Exp. Gerontol. 37, 1015-1021.

Hultmark, D., 2003. Drosophila immunity: paths and patterns. Curr. Opin. Immunol. 15, 12-19.

Kannisto, V., Christensen, K., Vaupel, J.W., 1997. No increased mortality in later life for cohorts born during famine. Am. J. Epidemiol. 145, 987 994.

Keller, L., Genoud, M., 1997. Extraordinary lifespans in ants: a test of evolutionary theories of ageing. Nature 389, 958-960.
Kenyon, C., 2001. A conserved regulatory system for ageing. Cell 105, 165 168.

Kenyon, C., Chang, J., Gensch, E., Rudener, A., Tabtiang, R., 1993. A C. elegans mutant that lives twice as long as wild type. Nature 366, 461464.

Kern, F., Bunde, T., Faulhaber, N., Kiecker, F., Khatamzas, E., Rudawski, I.M., et al., 2002. Cytomegalovirus (CMV) phosphoprotein 65 makes a large contribution to shaping the $\mathrm{T}$ cell repertoire in CMV-exposed individuals. J. Infect. Dis. 185, 1709-1716.

Khan, N., Shariff, N., Cobbold, M., Bruton, R., Ainsworth, J.A., Sinclair, A.J., Nayak, L., Moss, P.A.H., 2002. Cytomegalovirus seropositivity drives the CD8 T cell repertoire toward greater clonality in healthy elderly individuals. J. Immunol. 169, 1984-1992.

Kimura, K.D., Tissenbaum, H.A., Liu, Y., Ruvkun, G., 1997. daf-2, an insulin receptor-like gene that regulates longevity and diapause in Caenorhabditis elegans. Science 277, 942-946.

Klass, M.R., 1977. Ageing in the nematode Caenorhabditis elegans: major biological and environmental factors influencing life span. Mech. Ageing Dev. 6, 413-429.

Klass, M.R., Hirsh, D.I., 1976. Nonageing developmental variant of $C$. elegans. Nature 260, 523-525.

Lakowski, B., Hekimi, S., 1998. The genetics of caloric restriction in Caenorhabditis elegans. Proc. Natl. Acad. Sci. U.S.A. 95, 1309113096.

Leon, D.A., Lithell, H.O., Vagero, D., et al., 1998. Reduced fetal growth rate and increased risk of death from ischaemic heart disease: cohort study of 15,000 Swedish men and women born 1915-1929. BMJ 317, 241-245.

Leroi, A., 2001. Molecular signals versus the Loi de Balancement. Trends Ecol. Evol. 16, 24-29.

Lyman, C.P., O’Brien, R.C., Greene, G.C., Papafrangos, E.D., 1981. Hibernation and longevity in the Turkish hamster Mesocricetus brandti. Science 212, 668-670.

Lyytinen, A., Brakefield, P.M., Lindstrom, L., Mappes, J., 2004. Does predation maintain eyespot plasticity in Bicyclus anynana? Proc. Roy. Soc. London B 271, 279-283.

Magwere, T., Chapman, T., Partridge, L., 2004. Sex differences in the effect of dietary restriction on life span and mortality rates in female and male Drosophila melanogaster. J. Gerontol. A: Biol. Sci. Med. Sci. 59, 3-9.

Martin, G.M., Austad, S.N., Johnson, T.E., 1996. Genetic analysis of ageing: role of oxidative damage and environmental stresses. Nat. Genet. 13, 25-34.

Mattson, M.P., Chan, S.L., Duan, W., 2002. Modification of brain ageing and neurodegenerative disorders by genes, diet, and behavior. Physiol. Rev. 82, 637-672.

McCulloch, D., Gems, D., 2003. Evolution of male longevity advantage in nematodes. Ageing Cell 2, 165-173.

Mensua, J.L., Moya, A., 1983. Stopped development in overcrowded cultures of Drosophila melanogaster. Heredity 51, 347-352.

Mobbs, C.V., Bray, G.A., Atkinson, R.L., Bartke, A., Finch, C.E., Maratos-Flier, E., Crawley, J.N., Nelson, J.F., 2001. Neuroendocrine and pharmacological manipulations to assess how caloric restriction increases life span. J. Gerontol. A: Biol. Sci. Med. Sci. 56 (Spec No 1), 34-44.

Neel, J.V., 1962. Diabetus mellitus: a "thrifty" genotype rendered detrimental by "progress"? 353-362.

Nusbaum, T., Rose, R., 1999. The effects of nutritional manipulation and laboratory selection on lifespan in Drosophila melanogaster. J. Gerontol. A: Biol. Sci. Med. Sci. 54, B192-B198.

Oner, H., Ozan, E., 2002. Effects of gonadal hormones on thymus gland after bilateral ovariectomy and orchidectomy in rats. Arch. Androl. 48, 115-126.

Orr, W., Sohal, R., 2003. Does overexpression of Cu, Zn-SOD extend life span in Drosophila melanogaster? Exp. Gerontol. 38, 227-230.

Ozanne, S.E., Hales, C.N., 2004. Catch up growth and obesity in male mice. Nature 427, 411-412. 
Parker, J.D., Parker, K.M., Sohal, B.H., Sohal, R.S., Keller, L., 2004. Decreased expression of $\mathrm{Cu}-\mathrm{Zn}$ superoxide dismutase 1 in ants with extreme lifespan. Proc. Natl. Acad. Sci. U.S.A. 101, 3486-3489.

Partridge, L., Gems, D., 2002. Mechanisms of ageing: public or private? Nat. Rev. Genet. 3, 165-175.

Pittenger, C., Kandel, E.R., 2003. In search of general mechanisms for longlasting plasticity: aplysia and the hippocampus. Philos. Trans Roy. Soc. London B: Biol. Sci. 358, 757-763.

Ravelli, A.C.J., van der Meulen, J.H.P., Michels, R.P.J., et al., 1998. Glucose tolerance in adults after prenatal exposure to famine. Lancet 35, 173-177.

Riddle, D.L., Albert, P.S., 1997. Riddle, D.L., Blumenthal, T., Meyer, B.J., Priess, J.R. (Eds.), Genetic and environmental regulation of dauer larva development in C. elegans II. Cold Spring Harbor Laboratory Press, Plainview, NY, pp. 739-768.

Robinson, G., 1992. Regulation of division of labor in insect societies. Annu. Rev. Entomol. 37, 637-665.

Roseboom, T.J., van der Meulen, J.H.P., Ravelli, A.C.J., et al., 1999. Blood pressure in adults after prenatal exposure to famine. J. Hypertens. 17, 325-330.

Roth, G.S., Ingram, D.K., Joseph, J.A., 1993. Delayed loss of striatal neurons during ageing of dietary restricted rats. Brain Res. 300, 27-32.

Santer, R.M., Conboy, V.B., 1990. Prenatal undernutrition permanently decreases enteric neuron number and sympathetic innervation of Auerbach's plexus in the rat. J. Anat. 168, 57.

Saurwein-Teissl, M., Lung, T.L., Marx, F., Gschosser, C., Asch, E., Blasko, I., Parson, W., Bock, G., Schonitzer, D., Trannoy, E., Grubeck-Loebenstein, B., 2002. Lack of antibody production following immunization in old age: association with CD8(+) and CD28(-) T cell clonal expansions and an imbalance in the production of Th1 and Th2 cytokines. J. Immunol. 168, 5893-5899.

Schlichting, C.D., Pigliucci, M., 1998. Phenotypic Evolution, a Reaction Norm Perspective. Sinauser, Massachusetts, Sunderland.
Seminara, S.B., et al., 2003. The GPR54 gene as a regulator of puberty. N. Engl. J. Med. 349, 1614-1627.

Smith, D.W.E., 1993. Women Live Longer than Men in Human Longevity. Oxford University Press, New York, Oxford.

Stanner, S.A., Bulmer, K., Andrès, C., Lantseva, O.E., et al., 1997. Does malnutrition in utero determine diabetes and coronary heart disease in adulthood? Results from the Leningrad siege study, a cross-sectional study. BMJ 315, 1342-1349.

Tatar, M., Bartke, A., Antebi, A., 2003. The endocrine regulation of ageing by insulin-like signals. Science 299, 1346-1351.

Taylor, R.W., Barron, M.J., Borthwick, G.M., Gospel, A., Chinnery, P.F., Samuels, D.C., et al., 2003. Mitochondrial DNA mutations in human colonic crypt stem cells. J. Clin. Invest. 112, 1351-1360.

Trzonkowski, P., Mysliwska, J., Szmit, E., Wieckiewicz, J., Lukaszuk, K., Brydak, L.B., Machala, M., Mysliwski, A., 2003. Association between cytomegalovirus infection, enhanced proinflammatory response and low level of anti-hemagglutinins during the anti-influenza vaccination-an impact of immunosenescence. Vaccine 21, 3826-3836.

Vågerö, D., Leon, D., 1994. Ischaemic heart disease and low birth weight: a test of the fetal-origins hypothesis from the Swedish Twin Registry. Lancet 343, 260-263.

Viney, M.E., 1999. Exploiting the life cycle of Strongyloides ratti. Parasitol. Today 15, 231-235.

Wolkow, C., Kimura, K., Lee, M., Ruvkun, G., 2000. Regulation of $C$. elegans life-span by insulin-like signaling in the nervous system. Science 290, 147-150.

Wong, A.E., Boutis, P., Hekimi, S., 1995. Mutations in the $c l k-1$ gene of Caenorhabditis elegans affect developmental and behavioral timing. Genetics 139, 1247-1259.

Zijlstra, W.G., Steigenga, M.J., Brakefield, P.M., Zwaan, B.J., 2003. Simultaneous selection on two-components of life-history in the butterfly Bicyclus anynana. Evolution 57, 1852-1862.

Zwaan, B.J., 2003. Linking development and ageing. Sci. Ageing Knowledge Environ., pe32. 